\title{
PENINGKATAN KOMPETENSI KOMUNITAS WANITA PEMILIK USAHA KECIL MENENGAH MELALUI WORKSHOP PUBLIC SPEAKING
}

\author{
Agus Purbathin Hadi, Shinta Desiyana Fajarica, Tenri Waru, Novita Maulida \\ Program Studi Ilmu Komunikasi Universitas Mataram \\ J1. Majapahit No. 62, Gomong, Selaparang, Kota Mataram, Nusa Tenggara Barat \\ oppietaa@gmail.com
}

\begin{abstract}
Public Speaking used to be called rhetoric to become one of the disciplines of public communication. With the development of such public speaking as a public communication skills that helped shape success. Women Community Owners of Small and Medium Enterprises in Rarang village, Terara sub-district, East Lombok Regency are a group of women to develop individual potential. The output is increased knowledge, skills and skills in communication at both formal and informal forums. The problem for beginners in the community in public speaking is language skills, systematic and mental. This qualitative research method uses andragogy learning approach. The results of this study include public speaking training activities to improve their language skills. By using the training method obtained satisfactory results. Through this activity activity can increase the potential of speaking ability of the community of women owners of small and medium businesses in the village of Rarang. Besides being able to increase the participation of women in more formal public forums. Increasing the role of women will certainly also affect the capacity and capabilities of women in their involvement in public forums.
\end{abstract}

Keywords: communication, public speaking, business groups, women

\begin{abstract}
Abstrak
Public Speaking dulu disebut retorika menjadi salah satu disiplin ilmu komunikasi publik. Dengan perkembangan yang sedemikian rupa public speaking menjadi satu keterampilan komunikasi publik yang turut membentuk kesuksesan. Komunitas Wanita Pemilik Usaha Kecil Menengah Desa Rarang Kecamatan Terara Kabupaten Lombok Timur adalah kumpulan wanita guna mengembangkan potensi individu. Outputnya meningkatnya pengetahuan, keterampilan dan kemahiran dalam berkomunikasi pada forum baik formal dan non formal. Permasalahan bagi pemula di komunitas tersebut dalam public speaking adalah keterampilan berbahasa, sistematika dan mental. Metode penelitian kualitatif ini menggunakan menggunakan pendekatan pendidikan orang dewasa. Hasil dari penelitian ini meliputi aktivitas pelatihan public speaking meningkatkan keterampilan mereka dalam berbahasa. Dengan menggunakan metode pelatihan didapatkan hasil yang memuaskan. Melalui kegiatan ini menambah potensi kemampuan berbicara komunitas wanita dan mampu meningkatkan peran serta wanita di forum publik yang lebih formal. Peningkatan peran wanita mempengaruhi kapasitas dan kapabilitas wanita dalam keterlibatannya pada forum publik.
\end{abstract}

Kata Kunci: komunikasi, public speaking, kelompok usaha, wanita. 


\section{PENDAHULUAN}

$\begin{array}{lrr}\text { Komunikasi } & \begin{array}{r}\text { merupakan } \\ \text { aspek }\end{array} \\ \text { penting dalam } & \text { kehidupan untuk } \\ \text { berinteraksi satu sama lain. } & \text { Public }\end{array}$
speaking merupakan salah satu bagian dari aktivitas komunikasi. Public Speaking yang dulu dikenal dengan sebutan retorika, saat ini menjadi kebutuhan utama bagi manusia, dikarenakan kebutuhan komunikasi menjadi semakin sigifikan dan krusial yang merambah ke berbagai aspek kehidupan. Public speaking pun kemudian menjadi salah satu disiplin ilmu komunikasi publik. Dengan perkembangan yang sedemikian rupa public speaking menjadi satu keterampilan komunikasi publik yang wajib dimiliki oleh siapapun bila mereka ingin sukses dalam bidang ekonomi, sosial, politik bahkan budaya, sebab komunikasi yang dilakukan manusia dimuka bumi ini hampir 99\% dilakukan secara verbal (Sirait, 2007).

Sayangnya tidak semua orang bisa berkomunikasi dengan hebat secara alamiah. Untuk itulah pendidikan dan pelatihan komunikasi diperlukan. Disinilah letak pentingnya Perguruan Tinggi dengan fungsi edukasi, melalui kegiatan tridharma perguruan tinggi tenaga pengajar di dalamnya dapat berperan di tengah-tengah masyarakat, mereka diharapkan mampu mengatasi semua persoalan yang terjadi sekaligus mengajukan solusi yang adaptifkreatif dan hal ini tidak bisa lepas dari komunikasi terutama komunikasi lisan. Mengingat masyarakat adalah sebuah kelompok, maka kemampuan public speaking juga menjadi modal utama dalam aktivitas ini.

Pendekatan dalam meningkatkan kemampuan dan kualifikasi perempuan bisa juga melibatkan media berbasis teknologi. Seperti hasil dari Setiyaningsih (2019), perempuan seperti ibu rumah tangga harus memiliki kemampuan dalam berkomunikasi secara langsung maupun berbasis media teknologi.

Disinilah letak signifikansi aktivitas penelitian ini bagaimana komunitas wanita usaha kecil menengah nantinya mampu menjadi pembaharu bagi masyarakat lainnya terutama kaum wanita yang akan membawa kepada perubahan besar terhadap pola berpikir dan skill dengan kegiatan public speaking, sehingga kesulitan-kesulitan yang selama ini dihadapi dalam berkomunikasi dapat memiliki solusi dan menjadi kunci dari kesuksesan hidup para wanita pengusaha ini ke depannya.

Teori komunikasi yang bisa diterapkan terkait dengan studi ini adalah teori komunikasi massa atau kelompok. Komunikasi massa itu sendiri didefinisikan dalam tiga ciri:

1. Komunikasi massa diarahkan kepada audiens yang relatif besar, heterogen dan anonim.

2. Pesan-pesan yang disebarkan secara umum, sering dijadwalkan untuk bisa mencapai sebanyak mungkin anggota audiens secara serempak dan sifatnya sementara.

3. Komunikator cenderung berada atau beroperasi dalam sebuah organisasi yang kompleks yang mungkin membutuhkan biaya besar (Severindan \& Tankard, 2005: 4).

Komunikasi massa yang dimaksud disini bukanlah komunikasi massa media. Komunikasi secara umum peranannya sangat menentukan gerak kehidupan karena hampir semua aktifitas kita baik secara individual, kelompok, sosial, budaya, politik, ekonomi, agama, hubungan antar bangsa dilakukan dengan cara berkomunikasi terutama komunikasi lisan. Betapa mendasarnya peran dan 
fungsi komunikasi dalam kehidupan kita. Tanpa komunikasi, tiada kehidupan. Bergerak atau diamnya sebentuk makhluk hidup tergantung pada komunikasi yang dilakukannya.

Public Speaking merupakan salah satu dari aktivitas komunikasi massa (Suwatno, 2018). Menurut David Zarefsky, dalam Public Speaking Strategic for Success; "Public speaking is a continuous communication process in which messages and signals circulate back and forth between speaker and listeners." Mudahnya dapat diartikan: Public Speaking adalah sebuah proses komunikasi berkelanjutan, di mana pesan, simbol (komunikasi) (dan makna, ed; tambahan penulis) terus berinteraksi, antara pembicara dan para pendengarnya (Webster, 2012).

$$
\text { Aktivitas public speaking }
$$
diidentikkan sebagai sebuah aktivitas yang mampu melakukan perubahan besar pada audiens yang mendengarkannya. Bukti yang menunjukkan bahwa kegiatan public speaking mempunyai andil yang sangat besar terhadap perubahan bahwa seorang kopral kecil, veteran perang dunia II berhasil naik menjadi Kaisar Jerman. Dalam Kampf dengan tegas Hitler mengatakan bahwa keberhasilannya disebabkan oleh kemampuannya berbicara (Wrenc, 2012). Ich Konnte Reden, katanya lebih lanjut Hitler berkata Jede grosse bewegung auf dieser erde verdankt ihr wachsen den grosseren rednern und nicht den grossen schreibern (setiap gerakan besar di dunia ini dikembangkan oleh ahliahli pidato dan bukan oleh jago-jago tulisan). Lebih lanjut dia mengatakan bahwa seorang politikus muda berdiri menyampaikan pidatonya. Pidato yang pertama disampaikannya dan pidato yang paling tidak menarik. Hadirin gaduh, sehingga ia berkali-kali minta perhatian mereka. Hampir setiap kalimat disambut dengan teriakan, ejekan, dan tertawa. Politikus ini gagal dalam tugasnya. Sheil, seorang tua menasehatinya untuk belajar cara berpidato yang baik. Seminggu kemudian ia berhasil menyampaikan pidato yang memikat pendengarnya. Dalam sejarah Inggris, ia terkenal dengan nama Disraeli, diplomat inggris kelas wahid (Rahmat, 2011: 1-2).

\section{METODE PENELITIAN}

Kegiatan ini dilakukan sebagai bentuk penelitian sekaligus pengabdian pada masyarakat ini menggunakan pendekatan pendidikan orang dewasa (Andragogy learning approach) dalam meningkatkan pengetahuan, keterampilan dan kepercayaan diri komunitas wanita pemilik usaha kecil menengah. Prinsipprinsip action learning akan digunakan sehingga proses belajar dapat direncanakan dengan baik, kegiatan pendampingan terlaksana secara terstruktur dan sesuai kebutuhan, hasilnya dapat diobservasi serta dilakukan refleksi terhadap hasil kegiatan sehingga dapat dilakukan perbaikan (replan) untuk penyempurnaan. Secara konkrit, metode pelaksanaan program pengabdian masyarakat untuk penanggulangan komunikasi publik ini akan dilaksanakan dalam bentuk workshop atau lokakarya. Sebagai sebuah workshop untuk peningkatan kompetensi public speaking, maka tahapan kegiatan eksperimental ini dijabarkan demikian: 


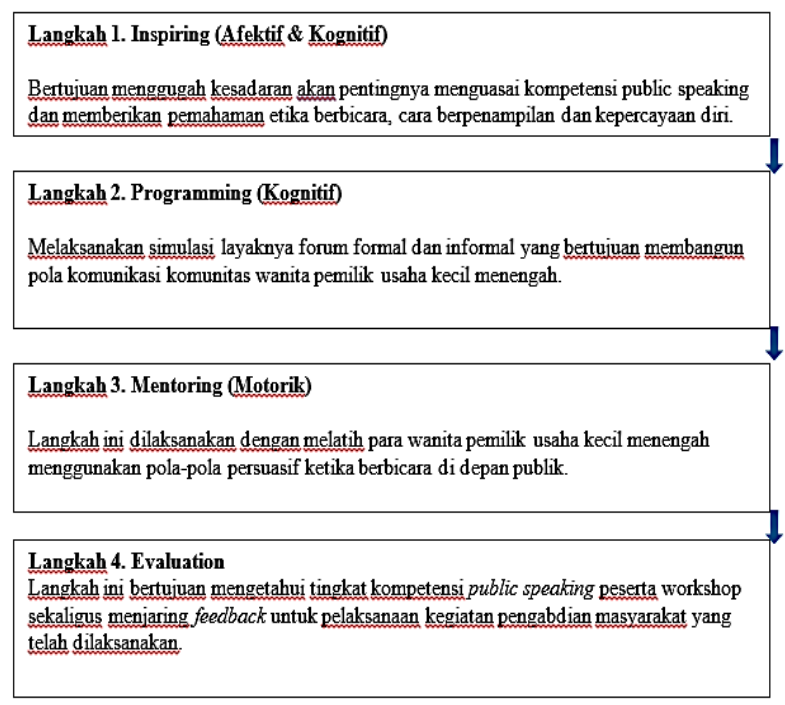

Gambar 1. Diagram Metode Pelaksanaan Kegiatan

\section{HASIL DAN PEMBAHASAN}

\section{Hasil}

Gambaran hasil kegiatan diawali dengan deskripsi singkat dari Komunitas Wanita Pemilik Usaha Kecil Menengah di Desa Rarang, Terara, Lombok Timur yang menjadi mitra kegiatan tim, pelaksanaan tahap inspiring, programming, mentoring dan evaluation. Sebagai satu rangkaian kegiatan maka tiga tahap awal, inspiring, programming dan mentoring dilaksanakan secara bersamaan. Sedangkan evaluasi dilaksanakan pada akhir workshop dengan mengadaptasi metodologi action research.

\section{Deskripsi Mitra}

Mitra kegiatan pengadian masyarakat ini adalah Komunitas Wanita Pemilik Usaha Kecil Menengah di Desa Rarang, Terara, Kabupaten Lombok Timur. Sebanyak 30 perempuan yang dipilih oleh Koordinator Komunitas menjadi peserta kegiatan workshop. Para perempuan yang dipilih dinilai layak dan mampu untuk menerima materi yang akan disampaikan, yang nantinya diharapkan menjadi pelopor dalam bersikap merubah pola pikir serta mengembangkan potensi bicara di muka publik secara lebih baik. Secara jelas, peserta workshop dan tim pelaksana serta narasumber pelatihan terlihat dalam gambar 2 .

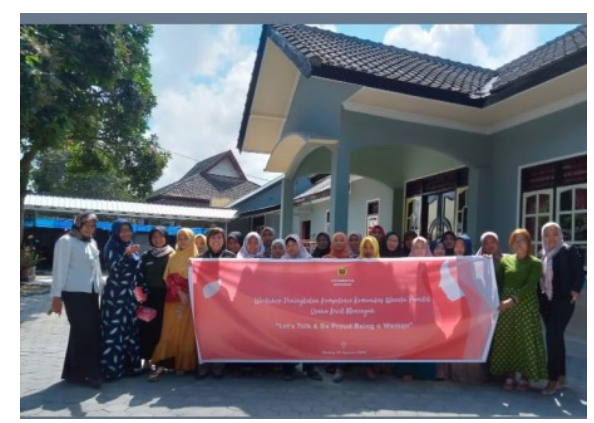

Gambar 2. Peserta Workshop Public

Speaking, Rarang, Kabupaten Lombok Timur

\section{Inspiring, Programming dan Mentoring}

Dalam melakukan aktivitas pengabdian, tim menggunakan metode Inspiring, Programming dan Mentoring. Adapun penerapan metode ini diharapkan dapat memberikan inspirasi bagi komunitas wanita pemilik usaha kecil menengah dalam mengembangkan potensi bicara berdasarkan pengalaman dari mentor dan perserta itu sendiri. Sebagai bahan evaluasi, tim melakukan pemetaan kemampuan peserta dengan cara memberikan stimulus melalui pertanyaan dan pernyataan. Kemudian, secara khusus, peserta diajak untuk mengenal secara lebih mendalam beberapa informasi dasar tentang public speaking, metode yang digunakan, serta apa saja yang dibutuhkan dalam rangka mempersiapkan diri menjadi public speaker yang handal. Metode yang digunakan dalam sesi ini adalah diskusi berdasarkan contoh konkrit dan pengalaman peserta di lapangan. 


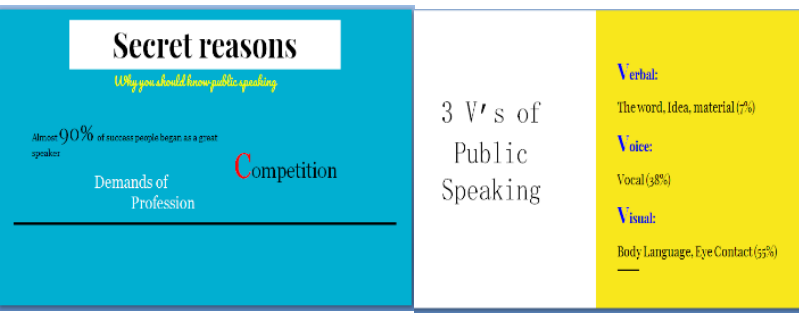

Gambar 3. Contoh Bahan Ajar

Praktik pelaksanaan public speaking yang dilakukan oleh peserta pelatihan, yang mencakup:

a. Pengenalan masalah internal

b. Memilih topik yang tepat

c. Menentukan metode penyampaian.

d. Inovasi dalam proses penyampaian pesan

Kepada para peserta diberikan juga beberapa contoh aplikasi penerapan aktivitas public speaking dan juga strateginya baik melalui tampilan video secara visual maupun praktik langsung. Dari beberapa pengamatan video yangdiberikan, peserta diminta untuk menganalisis permasalahan dan solusi yang ditawarkan. Contoh slide materi dalam hal ini terdapat pada gambar 4 .
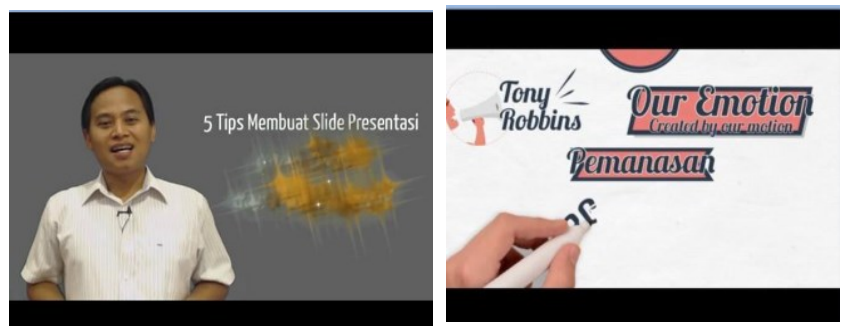

Gambar 4.

Strategi dan Tips dalam Public Speaking

\section{Evaluation}

Pada akhir kegiatan, dilakukan evaluasi terhadap perkembangan kemampuan/kompetensi peserta dalam mengaplikasikan aktivitas public speaking. Pengukuran kompetensi mencakup aspek kognitif, afektif dan konatif atau psikomotorik. Data dikumpulkan dengan menggunakan interpersonal approach melalui sesi interview. Pada sesi ini, peserta diberikan diajak berdiskusi tentang apa yang menjadi masalah terbesar di dalam melakukan kegiatan bicara di depan publik serta mencari solusi bersama dari aktivitas yang sudah dilakukan. Dari sesi interview yang dilakukan, maka hasilnya dapat dilihat pada tabel 1 berikut:

Tabel 1. Aspek \& Indikator Kompetensi Public Speaking

\begin{tabular}{|c|c|c|}
\hline No & Aspek & Indikator \\
\hline \multirow[t]{2}{*}{1} & \multirow[t]{2}{*}{ Kognitif } & $\begin{array}{l}\text { Membaca dan memahami materi Public } \\
\text { Speaking }\end{array}$ \\
\hline & & $\begin{array}{l}\text { Mengetahui satu/beberapa metode yang } \\
\text { digunakan }\end{array}$ \\
\hline \multirow[t]{2}{*}{2} & \multirow[t]{2}{*}{ Aspek Afektif } & $\begin{array}{l}\text { Merasa memiliki keinginan (antusiasme) } \\
\text { untuk punya kompetensi bicara di depan } \\
\text { publik ini }\end{array}$ \\
\hline & & $\begin{array}{l}\text { Mencoba untuk mengatasi rasa takut atau } \\
\text { gugup yang dimiliki }\end{array}$ \\
\hline \multirow[t]{2}{*}{3} & \multirow[t]{2}{*}{ Aspek Psikomotorik } & $\begin{array}{l}\text { Mencari solusi untuk mengatasi masalah } \\
\text { yang dihadapi dalam berbicara di depan } \\
\text { publik }\end{array}$ \\
\hline & & $\begin{array}{l}\text { Menggunakan media khusus untuk menjadi } \\
\text { alat bantu dalam melakukan aktivitas public } \\
\text { sveaking }\end{array}$ \\
\hline
\end{tabular}

\section{Pembahasan}

Materi yang diberikan meliputi: hakikat keterampilan berbicara. Materi tersebut disampaikan secara santai dan bersahabat. Teknisnya, tim menyampaikan materi secara bergantian. Dalam proses penyampaian materi, peserta diberi pengarahan bagaimana public speaking yang baik dalam meningkatkan kemampuan berbicara untuk menunjang kegiatan usaha mereka, selain itu diisi dengan diskusi kendala-kendala apa saja yang dihadapi dalam kegiatan usaha yang mereka jalani.

Sama halnya dengan pemberdayaan yang dilakukan pada ibu rumah berpenghasilan rendah, untuk meningkatkan kemampuan ekonomi dan keterampilan perempuan dimulai dari mengembangkan potensi keterampilan 
pembuatan kerajinan tangan talenan vintage serta mereka mampu memasarkan secara mandiri melalui iklan on line yang sifatnya gratis. Sehingga mitra bisa menjadi perempuan yang mandiri dan berdaya (Setiyaningsih, 2017).

Hal tersebut merupakan kegiatan yang hampir sama untuk mengembangkan dan meningkatkan kemampuan dasar seperti kemmapuan public speaking. Selama kegiatan berlangsung, peserta dikondisikan oleh tim untuk aktif. Rangkaian motivasi dan stimulasi selalu dilakukan oleh tim untuk membangun kegairahan peserta, sehingga mampu aktif dalam diskusi dan diharapkan ilmu yang disampaikan dapat tertransfer dengan baik.

Dalam diskusi ini, strategi yang dipilih adalah strategi kronologis. Strategi ini dilakukan dengan cara memberikan sesuatu secara bertahap, mulai dari yang ringan, hingga pada tahap yang lebih berat. Adapun langkah-langkah pentrasferan ilmu public speaking yang akan dilakukan kepada mitra, mengikuti penahapan sebuah rencana pembicaraan yang disampaikan Tarigan (2008) dan dikolaborasikan dengan ide tim pengabdian, antara lain sebagai berikut :

1. Tahap memilih pokok pembicaraan yang menarik hati. Dalam hal ini, tim pengabdian memberikan materi dasar yang mengarah pada pemahaman mitra untuk memilih topik pembicaraan yang menarik, baik menurut diri sendiri maupun masyarakat pada umumnya. Materi dasar ini adalah pengantar public speaking yang di dalamnya mencakup hakikat keterampilan berbicara, hakikat public speaking, dan teknik sederhana merancang public speaking.

2. Tahap membatasi pokok pembicaraan. Pada tahap ini, mitra diarahkan untuk menyempitkan topik yang akan disampaikan. Tim pengabdian memberi penekanan bahwa topik yang benar dan menarik adalah topik yang sempit dan mendalam. topik-topik tersebut seperti membawakan bagaimana cara berkomunikasi yang baik dengan strategi Public Speaking untuk meningkatkan usaha yang sedang dirintis

3. Tahap mengumpulkan bahan-bahan. Tahap ini menekankan adanya upaya untuk mencari referensi yang berhubungan dengan topik yang akan disampaikan kepada audiens. Bahan yang dibutuhkan dapat diakses dari berbagai sumber, seperti berita, informasi orang lain, maupun pengalaman pribadi. Bahan-bahan ini untuk memperkuat data mengenai apa yang disampaikan kepada audiens. Sebagian besar, peserta lebih memilih pengalaman pribadi dan berita di surat kabar sebagai bahan referensi.

4. Tahap menyusun bahan. Pada tahap ini, mitra diarahkan untuk mengembangkan rancangan yang telah disusun. Adapun bagian ini meliputi: (a) pendahuluan; (b) isi; dan (c) simpulan. Untuk mempermudah pelaksanaan, peserta diarahkan untuk berkelompok. Agar efektif, satu kelompok maksimal lima orang. Tim membimbing peserta secara intensif, baik mengenai pilihan kata, pengembangan kalimat, maupun praktik sederhana.

5. Tahap tampil secara percaya diri. Tahap ini merupakan tahap puncak dalam kegiatan public speaking. Pada tahap ini, mitra dibimbing oleh tim pengabdian untuk tampil secara individual menyampaikan pesan yang telah disiapkan kepada audiens. 
Peserta antusias untuk tampil berbicara. Ketika ada yang tampil, peserta yang belum mendapatkan giliran bertugas menjadi audiens yang mendukung jalannya acara.

6. Tahap evaluasi. Tahap ini adalah tahap terakhir dalam kegiatan public speaking. Setelah mitra tampil di depan forum, langsung diadakan evaluasi mandiri dan kelompok untuk memperbaiki penampilan pada saat berikutnya. Teknis pelaksanaannya, tim berkualitas, percaya diri, dan meyakinkan.

Berdasarkan evaluasi terhadap kegiatan yang telah dilakukan, bisa diketahui kegiatan ini cukup berhasil. Indikator keberhasilan ini meliputi: (1) adanya antusias minat peserta pelatihan yang ditunjukkan dengan banyaknya peserta yang bertanya dan menanggapi materi yang diberikan oleh tim; (2) keseriusan peserta mengikuti rangkaian acara yang diselenggarakan oleh tim dari awal sampai akhir acara; dan (3) semangat peserta untuk tampil praktek public speaking setelah materi selesai.

Meski di satu sisi ada point keberhasilan, akan tetapi kelemahan pastilah ada. Beragamnya jenjang pendidikan memengaruhi tingkat kompetensi peserta. Peserta dari jenjang SMP terlihat banyak diam dibandingkan peserta yang telah menapaki jenjang SMA/SMK dan perguruan tinggi. Hal ini dikarenakan daya tangkap dan tingkat kualitas logika yang mereka miliki berbeda.

Dari paparan dan tahap yang dilakukan tim pengabdian tentang pengertian public speaking diatas, tentu kita mengetahui bahwa sebuah teknik bicara sangatlah mempengaruhi pola pikir seseorang, oleh karena itu kita perlu dan butuh keterampilan berbicara efektif secara khusus, berupa sikap dan teknik berbicara yang tepat agar kitaa bisa melakukan itu semua, baik dalam penyampaian pesan, mempengaruhi orang, memotivasi dan lain sebagainya.

\section{PENUTUP}

\section{Simpulan}

Dalam mengatasi masalah rendahnya kemampuan public speaking anggota komunitas wanita pemilik usaha kecil menengah di Desa Rarang Lombok Timur tim pengabdian mengadakan kegiatan pelatihan mengenai teknik dan strategi public speaking agar mereka memahami dan dapat mempraktikkan kegiatan tersebut dengan baik dan percaya diri. Dengan demikian, mereka memiliki bekal secara teori dan praktik tentang public speaking yang baik. Adanya peningkatan kompetensi public speaking secara cerdas, benar, dan berkualitas terhadap anggota komunitas wanita pemilik usaha kecil menengah di Desa Rarang Lombok Timur menunjukan keberhasilan dari kegiatan pelatihan ini. Berbicara merupakan salah satu ketrampilan aktif dalam berbahasa. Selain peserta memahami kemampuan berbicara secara teoritis yang didapatkan dari pelatihan ini, mereka diharapkan untuk sering berlatih dan mempraktekannya.

Berdasarkan penjelasan dan uraian di atas, dapat disimpulkan bahwa public speaking mampu memberikan konstribusi terhadap kompetensi wanita dalam melakukan aktifitas di forum publik. Seorang wanita perintis usaha kecil menengah kini menjadi lebih mudah melaksanakan kegaiatan usahanya karena banyaknya bekal yang ia miliki dari workshop atau pelatihan yang telah diikuti. 


\section{Saran}

Kegiatan pelatihan sekaligus penelitian tindakan ini memiliki keterbatasan baik pada jumlah peserta atau sampel maupun kelengkapan instrumen penelitian sekaligus instrumen intervensi khususnya ketiadaan pelatihan dan pengukuran atas penerapan aktivitas public speaking. Untuk itu, tindakan selanjutnya dapat melengkapi berbagai instrumen pada setiap aspek agar peningkatan kompetensi public speaking dapat tercapai secara optimal.

\section{DAFTAR PUSTAKA}

Brendt D. Ruben dan Lea P. Stewart, (2013). Communicztion and human behaviour, Terj. Ibnu Hamad, Komunikasi dan Prilaku Manusia, Jakarta: Rajagrafindo.

Ibrahim, Idi Subandy. (2014). Kecerdasan Komunikasi Seni Berkomunikasi Kepada Publik. Bandung: Simbiosa Rekatama Media.

Rahmat, Jalaluddin. (2011). Retorika Modern Pendekatan Praktis. Bandung: Remaja Rosdakarya.

Setiyaningsih, L. A. (2017). PELATIHAN HANDYCRAFT TALENAN VINTAGE DAN CYBER PROMOTION UNTUK IBU

RUMAH TANGGA

BERPENGHASILAN RENDAH KELURAHAN KASIN KOTA MALANG. Jurnal Pengabdian Masyarakat Universitas Merdeka Malang, 1(1).

Setiyaningsih, L. A., \& Jatmikowati, S. H. (2019). Media Baru Dalam Komodifikasi Waktu Luang Ibu Rumah Tangga. ETTISAL: Journal of Communication, 4(1), 23-32.

Suwatno. (2018). Pengantar Public Relations Kontemporer. Bandung: PT. Remaja Rosda Karya

Sirait, Charles Bonair. (2007). The Power of Public Speaking: Kiat Sukses Berbicara di Depan Publik. Jakarta: Gramedia Pustaka.

Tarigan, Henry Guntur. (2008). Berbicara Sebagai Suatu Keterampilan Berbahasa. Bandung : Penerbit Angkasa.

Severin, Werner J., Tankard, James W. (2005). Teori Komunikasi. Jakarta: Prenada Media.

Webster, Linda J. (2012). Introduction to Public speaking. America Louisiana State University: Fountainhead Press.

Wrenc, Jason S. (2012). Public speaking Practice and Ethics. New York: Unnamed Publisher. 